\title{
PERANCANGAN BATIK TULIS DENGAN MEMANFAATKAN VISUAL GRAFFITI
}

\author{
Yati Anwar Munawaroh, Adji Isworo Josef \\ FSRD, Universitas Sebelas Maret \\ E-mail: yatianmu@student.uns.ac.id
}

\begin{abstract}
Abstrak
Batik merupakan budaya yang berasal dari rakyat dan selalu berkembang mengikuti zaman dan lingkungan. Pengembangan dari perancangan batik dilakukan untuk membuka kemungkinan-kemungkinan baru ke arah yang lebih luas lagi, dengan eksplorasi visual dan berani menerobos batasan-batasan batik konvensional. Tujuan dari perancangan batik ini adalah menghasilkan variasi produk batik tulis yang ditujukan untuk wanita usia 19- 25 tahun. Metode yang digunakan terdiri dari metode perancangan dengan teori Collin Clipson, konsep perancangan, dan visualisasi. Seluruh rancangan desain memanfaatkan visual graffiti menjadi motif utama. Visual graffiti menjadikan batik yang dikembangkan unik, karena tidak hanya sebagai bentuk ekspresi seni, graffiti juga digunakan sebagai media komunikasi. Kata atau kalimat yang diolah menjadi graffiti menggunakan tema streetfood yang ada di Indonesia. Pengolahan nama streetfood Indonesia yang dieksplor menjadi graffiti diambil sebagai simbol budaya populer yang ada di Indonesia dengan tetap mempertahankan nilai tradisi pada batik itu sendiri. Hasil dari perancangan ini adalah produk berupa kain batik dan busana ready-to-wear.
\end{abstract}

Kata Kunci: batik tulis, graffiti, streetfood

\section{BATIK TULIS DESIGN USING VISUAL GRAFFITI}

\begin{abstract}
Batik is a people-based culture that evolves with the times and the surroundings. By aesthetic research and daring to push the limitations of conventional batik, the evolution of batik design aims to offer new possibilities in a larger direction. This batik design intends to provide a variety of written batik products aimed at women between 19 and 25. The design process employed combines Collin Clipson theory, design concepts, and visualization. Each design incorporates visual graffiti as the primary motif. Visual graffiti distinguishes developed batik from others, as graffiti is utilized as a means of communication in addition to aesthetic expression. Words or statements that have been transformed into graffiti use the theme of Indonesian street food. The transformation of Indonesian street food names into graffiti serves as a sign of popular culture in Indonesia while preserving the traditional value of batik. The results of this design are batik cloth and readyto-wear clothing.
\end{abstract}

Keywords: batik tulis, graffiti, streetfood 


\section{PENDAHULUAN}

Batik menjadi salah satu warisan budaya Indonesia yang sudah ada sejak dulu. Teknik merintang warna dengan malam atau lilin ini sudah menjadi kerajinan yang umum dan banyak digunakan sehari-hari. Batik juga telah banyak dikombinasikan dengan motif lain atau diterapkan bukan hanya untuk pakaian melainkan produk lainnya. Batik merupakan budaya yang berasal dari rakyat dan selalu berkembang mengikuti zaman dan lingkungan. Fakta-fakta yang ada menjadi bukti bahwa zaman dan lingkungan mempengaruhi proses perkembangan batik hingga sekarang (Santosa, 2002).

Perancangan batik tulis dengan sumber ide motif dari gaya visual graffiti diambil berdasarkan alasan berkembangnya batik kontemporer. Graffiti adalah istilah yang digunakan untuk penulisan maupun gambar-gambar yang digores, dicoret- coret, dicat, atau ditorehkan di dinding. Terdapat beberapa jenis graffiti berdasarkan bentuknya, antara lain adalah graffiti tagging, blockbuster, throwup, piece, stencil, character (street logos), dan realis (Susanto, 2012). Visual graffiti menjadi sumber ide yang digunakan untuk perancangan batik dikarenakan dapat memberikan gaya baru dalam membuat motif batik. Belum ditemukannya implementasi visual graffiti yang kental akan seni jalanan atau street art pada batik kontemporer membuat inovasi ini menjadi nilai kreasi yang menarik. Tidak hanya sebagai bentuk ekspresi seni, graffiti juga digunakan sebagai media komunikasi. Di zaman purba, manusia primitif mulai menerapkan media komunikasi untuk menyampaikan pesan perburuan melalui coretan di dinding. Fenomena ini dianggap sebagai salah satu awal-mula munculnya seni graffiti. Di Barat, seni graffiti juga erat hubungannya dengan budaya hip-hop sekaligus sebagai sarana komunikasi politik dan sosial (Naguib, 2016:59)
Perancangan motif batik kontemporer sudah banyak dilakukan, seperti yang dilakukan oleh Connie Ayu Natanhia dalam perancangan Tugas Akhir dengan judul Kekayaan Bahari Indonesia sebagai Sumber Ide Perancangan Batik Gaya Doodle (2016) menghasilkan visual batik kontemporer. Begitu pula dalam perancangan Desain Motif Batik Kontemporer dengan Sumber Ide Robot (2014) oleh Arief Satriyo Wibowo dengan hasil perancangan batik yang tidak semuanya mengikuti aturan batik tradisi. Hasil dari perancangan batik tersebut motif yang dihasilkan berbeda dengan batik tradisi yang harus memiliki motif utama, motif pendukung, dan isen. Berdasarkan contoh batik kontemporer yang sudah pernah dibuat maka dapat disimpulkan bahwa dalam pembuatan batik kontemporer berbeda dengan batik tradisi yang memiliki motif lengkap.

Desain graffiti yang begitu fleksibel merupakan sebuah kelebihan karena dapat diterapkan untuk berbagai tujuan termasuk di dalamnya strategi diplomasi. Indonesia merupakan negara yang kaya akan budaya hingga tradisi tak terkecuali ragam olahan kuliner khas. Diplomasi kuliner muncul sebagai salah satu alternatif dalam hubungan internasional dalam bentuk gastrodiplomasi (gastrodiplomacy). Diplomasi budaya ini menggunakan makanan sebagai sarana untuk meningkatkan brand awareness bangsa secara lebih signifikan dan efektif (Rockower, 2014).

Streetfood atau jajanan kaki lima selanjutnya diambil sebagai tema dari pemilihan kata atau kalimat graffiti yang akan diaplikasikan dalam kain batik.. Hal ini dilatarbelakangi oleh fenomena streetfood seperti sudah menjadi gaya hidup sebagian besar orang, terutama anak muda. Keberadaannya pun mudah ditemui di mana saja dan kapan saja. Menurut Food and Agriculture (FAO) mendefinisikan streetfood atau 
makanan jajanan adalah makanan dan minuman yang disiapkan dan dijual pedagang kaki lima di pinggir jalan dan di tempat umum untuk langsung dimakan atau dikonsumsi tanpa adanya pengolahan maupun persiapan lebih lanjut.

Kombinasi batik dengan motif graffiti dengan desain streetfood Indonesia menjadi media promosi sekaligus teknik pelestarian budaya yang efektif. Graffiti yang merupakan bentuk ekspresi dari budaya modern dan secara bersamaan dapat dimanfaatkan untuk mempertahankan suatu budaya atau tradisi tertentu (Tsoumas, 2011:1). Oleh karena itu, perancangan batik tulis dengan visual graffiti dapat menambah ragam jenis motif batik di Indonesia. Selain itu perancangan diharapkan dapat menjadi sarana edukasi mengenai perkembangan motif batik dan dapat mengkombinasikan antara teknik batik yang tradisional dengan budaya street art berupa motif graffiti yang dekat dengan anak muda. Hasil perancangan batik dengan memanfaatkan visual graffiti menjadi motif batik dengan mempertahankan karakteristik dari graffiti dan batik divisualisasikan melalui eksplorasi desain graffiti sehingga cocok dan mudah untuk dibatik. Pemilihan jenis graffiti juga menjadi dasar untuk perancangan desain. Visual graffiti yang biasa terlihat di ruang publik dengan huruf- huruf yang seringkali tidak dapat terbaca diolah menjadi lebih mudah untuk dibaca. Pesan atau tulisan pada graffiti yang biasanya berupa inisial suatu kelompok ataupun individu diolah menjadi graffiti yang mengangkat tradisi ataupun budaya yang ada Indonesia. Pemilihan kata/ kalimat untuk desain graffiti adalah dengan mengambil tema streetfood Indonesia. Tema streetfood dibagi menjadi beberapa kategori agar memudahkan dalam membuat desain. Pengambilan tema budaya ini sekaligus agar tidak mengurangi esensi nilai- nilai tradisi pada batik.

\section{METODE}

Merancang menurut Collin Clipson (dalam Rizali, 2018) adalah menterjemahkan kebutuhan, tujuan dan gagasan pemakai sesuai dengan kriteria teknologi, sosial dan lingkungan dengan mempertimbangkan fungsi dari produk atau jasa mengacu pada pasar dan pembeli. Untuk mencapai tujuan dari perancangan, maka diperlukan beberapa pertimbangan di dalam prosesnya, diantaranya adalah pasar sasaran, pangsa sasar, persaingan dan sikap, perilaku, dan daya beli konsumen.

Proses perancangan melewati tahap identifikasi permasalahan, merupakan pengenalan terhadap masalah desain dan identifikasi mengenai kebutuhan yang harus dipenuhi. Menganalisa perancangan melalui kajian teoritik dan empirik. Kemudian proses selanjutnya akan sampai kepada gagasan awal perancangan yang merupakan bagian dari proses kreatif. Kemudian hasil desain yang dipilih akan sampai kepada proses produksi.

\section{Analisis Permasalahan}

Fokus permasalahan berupa cara mengembangkan dari batik tulis kontemporer dengan visual grafiti menimbulkan beberapa permasalahan. Pertama, permasalahan teknik penggambaran graffiti dapat dijadikan menjadi motif batik, namun kesan graffiti berupa gaya penulisan tetap muncul, dan visual dari batik juga tetap kuat. Kedua, permasalahan dalam perancangan batik dengan tema graffiti apakah tetap menggunakan unsur dari batik berupa motif utama, motif pendukung, dan isen. Kemudian yang ketiga adalah visual dari graffiti kebanyakan berukuran besar dan banyak menggunakan garis lurus akan menyulitkan ketika proses membatik karena perancangan menggunakan teknik batik tulis. Keempat, yaitu perwujudan produk busana wanita yang ditujukan untuk rentang usia 1925 tahun. 


\section{Strategi Pemecahan Masalah}

Strategi dalam menyelesaikan permasalahan pada perancangan dilakukan dengan mencari referensi-referensi mengenai perkembangan motif batik kontemporer dan jenis-jenis graffiti. Batik kontemporer sendiri merupakan batik kreasi baru dengan motif dan isen tidak harus mengikuti pakem asalkan sesuai dengan pengertian batik yaitu dengan perintangan warna menggunakan lilin/ malam. Pemilihan jenis graffiti yang tidak menggunakan garis lurus yang panjang juga dapat membantu untuk mempermudah dalam membatik. Pengolahan visual dan perancangan model busana yang kasual menjadi alternatif agar dapat difungsikan untuk busana wanita usia 19- 25 tahun. Pemilihan model busana yang kasual diharapkan dapat digunakan dalam jangka waktu yang lama.

\section{Pengumpulan Data}

Pengumpulan data dilakukan untuk mendukung perancangan agar sesuai dengan tujuan yang diinginkan.

1. Studi Visual produk dengan visual graffiti

Studi visual dilakukan berupa pengumpulan data visual dari jenis-jenis graffiti dan perkembangannya. Karakteristik gaya graffiti yang banyak terdapat di tembok kota dapat membantu dalam mengolah visual graffiti dalam perancangan batik tulis. Studi visual graffiti juga melalui berbagai platform media sosial yang membahas atau menampilkan aktivitas dan perkembangan graffiti

Studi visual dilakukan dengan mencari referensi dari produk yang sudah pernah dibuat dengan tema graffiti. Beberapa brand busana, sepatu, dan tas pernah megeluarkan produk dengan tema graffiti.

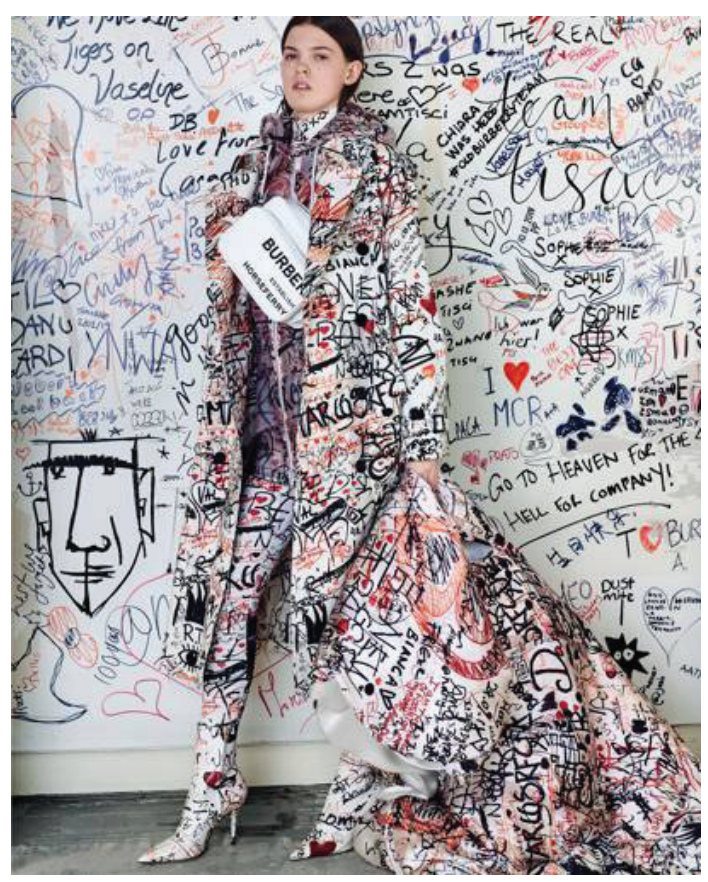

Gambar 1. Koleksi dari Burberry dengan tema graffiti

(Sumber: https://www.vogue.co.uk/shows/ spring-summer-2020-resort/burberry)

2. Studi visual produk batik kontemporer

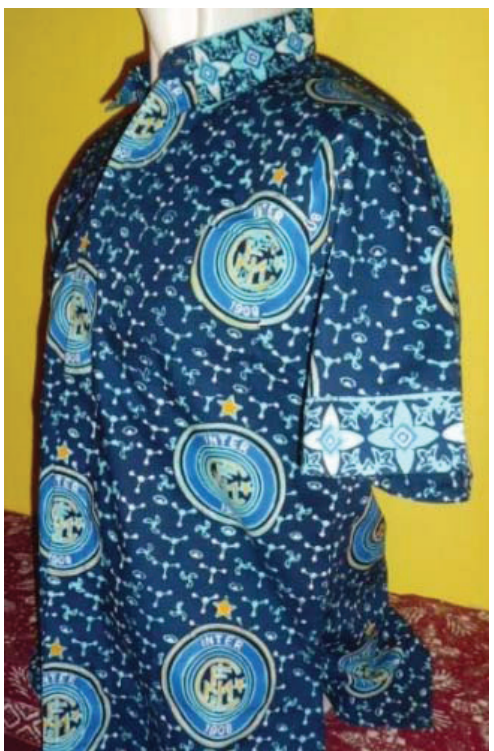

Gambar 2. Batik kontemporer tema piala dunia

(Sumber: http://donatacollection.blogspot. com/) 
Beberapa contoh batik kontemporer menunjukkan bahwa visual dapat berupa apa saja seperti pengembangan motif batik tradisi dan dapat pula berupa suatu peristiwa yang banyak orang mengetahui. Visual tidak jauh dari perkembangan, sumber daya, maupun budaya yang ada di masyarakat. Karakterisitik batik kontemporer dapat berupa pengembangan dari motif batik yang sudah ada maupun motif-motif baru yang bukan merupakan motif dari batik klasik atau pesisiran. Motif-motif baru ini banyak menghasilkan visual yang sesuai perkembangan zaman, dan beberapa juga hanya berupa motif utama tanpa pendukung atau tanpa isen.

\section{HASIL DAN PEMBAHASAN \\ Gagasan Awal Perancangan}

Berdasarkan studi visual dan penelitian terkait sebelumnya didapatkan gagasan awal perancangan batik kontemporer dengan tema graffiti yang akan menggunakan salah satu atau penggabungan dari jenis graffiti yang ada. Peggambaran visual graffiti juga akan dibuat dengan ukuran yang tidak terlalu besar agar dalam pengerjaanya akan lebih mudah untuk dibatik. Pemilihan untuk kata atau kalimat graffiti berkaitan dengan nilai-nilai kearifan lokal maupun budaya Indonesia sehingga tidak mengurangi nilai batik sendiri. Desain kata atau kalimat yang digunakan untuk perancangan batik menggunakan tema streetfood Indonesia. menggunakan graffiti jenis wildstyle, bubble, dan tagging dengan visual yang lebih mudah untuk dibaca. Sasaran konsumen adalah wanita dengan rentang usia 1925 tahun. Desain batik yang akan dibuat kemudian akan diaplikasikan menjadi produk fungsional berupa produk busana wanita ready to wear dengan mempertimbangkan komposisi desain yang sesuai.

\section{Batik}

Batik menurut teknik pembuatannya (Prasetyo, 2016) dibedakan menjadi:

a. Batik tulis, yaitu kain yang dihias dengan tekstur dan corak batik menggunakan tangan dengan alat berupa canting. Proses pembuatan batik tulis memakan waktu sekitar 2-3 bulan

b. Batik cap, yaitu teknik batik yang dibuat dengan menggunakan cap (biasanya terbuat dari tembaga). Proses pembuatan batik jenis ini membutuhkan waktu kurang lebih 2-3 hari

c. Batik lukis, yaitu proses pembuatan batik dengan cara langsung melukis pada kain.

Macam batik secara garis besar dibagi menjadi tiga macam yaitu, batik tradisi, batik semi tradisi, dan batik kreasi/kontemporer. Batik tradisi adalah batik yang terikat dengan tradisi tertentu. Batik semi tradisi merupakan pengembangan motif dari batik tradisi dengan sedikit mengubah motifnya. Sedangkan batik kreasi atau kontemporer merupakan batik modern yang motif, gaya, dan teknik lebih dikembangkan termasuk motif dan isen-isen yang tidak harus mengikuti pakem atau tradisi tertentu. Batik kontemporer dibuat berdasarkan ide, kreatifitas, dan keinginan dari seniman yang akan membuatnya. Sumber ide untuk batik kontemporer juga menyeseuaikan dengan perkembangan zaman dan masa kini.

\section{Graffiti}

Menurut Wicandra dan Angkadjaja (2005), asal kata "graffiti" adalah jamak dari "graffito". Sejarah penggunaan kata graffiti mengacu pada pembuatan suatu karya seni dengan teknik menggores/ mengguratkan suatu desain pada permukaan tertentu. Perbedaan antara graffiti dan mural adalah objeknya, jika pada graffiti menekankan teknik 
stilasi dari rangkaian huruf dan banyak dikerjakan dengan menggunakan cat semprot (air brush), sedangkan pada mural lebih pada kemampuan menggambar objek (drawing).

\section{Streetfood}

Makanan jajanan (streetfood) terdiri dari minuman, kudapan atau makanan kecil, dan makanan lengkap, yang didefinisikan sebagai makanan siap makan atau dimasak di tempat penjualan, dan di jual di pinggir jalan, atau di tempat umum (Winarno,1993). Konsep nation branding didefinisikan sebagai sekumpulan teori dan penerapan yang memiliki tujuan untuk mengukur, membangun, hingga mengatur reputasi suatu negara. Nation branding juga memiliki tujuan yang jelas yakni menggunakan citra negara guna mempromosikan produk dalam negeri, meningkatkan ekspor, mempromosikan dengan citra bangsa, membuat orang lain melihat suatu negara berbeda dengan negara lain, membangun identitas nasional suatu negara, menarik wisatawan, serta meningkatkan investasi asing (Kaneva, 2011)

\section{Busana Ready to Wear}

Busana dalam arti umum adalah bahan tekstil atau bahan lain yang sudah dijahit tidak dijahit yang dipakai maupun atau disampirkan untuk menutup tubuh seseorang (Riyanto, 2003). Ada tiga fungsi busana, yaitu sebagai alat pelindung, sebagai alat penunjang komunikasi dan sebagai alat memperindah. Ready to wear atau Prêt à Porter adalah busana siap pakai yang diproduksi secara massal, dalam berbagai ukuran dan warna berdasarkan satu desain yang membawa label nama seorang desainer. Busana ini dapat langsung dikenakan tanpa harus melakukan pengukuran badan lebih dahulu. kategori Busana ready to wear selain busana gaya street style, termasuk di dalamnya adalah busana pesta dan busana kerja. Biasanya busana ready to wear menggunakan potongan mini- malis, penggunaan bahan yang efisien, pola yang tidak rumit, serta harga jual yang lebih terjangkau oleh pembeli (Poespo, 2009).

\section{Proses Perancangan}

Perancangan desain motif batik ini adalah dengan memanfaatkan visual graffiti sebagai motif. Perancangan akan memadukan visual graffiti yang banyak terdapat di ruang publik kota-kota besar menjadi sebuah produk batik yang sarat akan nilai-nilai tradisi. Perpaduan karakter graffiti dengan teknik batik akan menjadi produk inovatif dalam pengembangan batik tulis. Perancangan batik dibuat dengan mempertimbangkan beberapa aspek, diantaranya adalah aspek estetis, aspek teknik, aspek bahan, dan aspek material yang digunakan.

1. Aspek Teknik

Aspek teknik merupakan proses dalam mewujudkan hasil akhir produk sesuai desain yang dibuat. Teknik batik tulis dipilih karena dapat mewujudkan visual desain dengan lebih nyata sesuai perancangan dan juga lebih ekspresif. Desain yang akan direalisasikan di atas permukaan kain menjadi batik melalui cara dengan perintangan malam, diwarna, lalu dilorod.

2. Aspek Bahan

Bahan merupakan material yang digunakan untuk mewujudkan perancangan menjadi produk dan juga kualitas dari suatu produk. Pemilihan bahan yang sesuai akan membuat perancangan yang dibuat sesuai dengan hasil yang diinginkan baik dari segi bentuk, warna, maupun fungsinya. Bahan yang digunakan untuk perancangan batik ini adalah bahan katun primisima. Bahan ini dipilih karena dapat memunculkan warna sesuai dengan perancangan, harga yang terjangkau, dan nyaman untuk digunakan.

3. Aspek estetis

Aspek estetis dalam perncangan ini adalah dengan memunculkan masing-masing ciri khas dari graffiti dan batik. Motif berupa vi- 
sual graffiti dibuat dengan jenis graffiti wildstyle, bubble dan tagging. Visual dari tema streetfood dan graffiti dan penambahan isenisen dibuat agar karakter batik tetap muncul. Karakter graffiti jenis bubble tetap dibuat sepertinya aslinya, sedangkan untuk jenis wildstyle dibuat dengan desain lebih simpel sehingga masih dapat dibaca karena kebanyakan grafffiti jenis wildstyle sangat ekspresif dan seringkali susah untuk dibaca. Karakter graffiti jenis tagging dibuat seperti visual aslinya. Perpaduan ketiga jenis graffiti diharapkan dapat membuat motif batik tidak terlalu monoton.

\section{Aspek fungsi}

Perancangan batik tulis ini akan difungsikan sebagai busana berupa busana wanita ready to wear untuk usia 19- 25 tahun. Desain busana ready to wear lebih mengarah kepada busana kasual dengan model yang simpel.

\section{Visualisasi}

Visualisasi desain merupakan proses untuk mewujudkan ide, konsep dari sebuah perancangan. Visualisasi yang dipilih sebagai motif batik lebih kepada karakter visual graffiti yang didukung dengan isen-isen batik sehingga dapat lebih harmonis antara visual graffiti dengan karakter batik. Jenis graffiti yang digunakan untuk perancangan hanya menggunakan jenis graffiti yang cocok dan mudah untuk dibatik. Graffiti yang biasanya terdapat pada dinding dengan ukurannya yang besar akan dirancang dengan ukuran yang lebih kecil sehingga akan lebih mudah untuk dibatik.

Proses pewarnaan untuk batik ini dengan menggunakan pewarna remasol karena dapat menghasilkan warna-warna yang cerah dan menyesuaikan dengan desain batik yang dibuat. Bahan yang digunakan adalah katun primissima yang akan difungsikan sebagai busana wanita.
Visualisasi perancangan batik tulis dengan memanfaatkan visual graffiti dibuat dengan tema streetfood di Indonesia. Produk direalisasikan untuk busana wanita usia 1925 tahun dan kain ukuran 2,5 meter. Jenis graffiti yang digunakan dalam mengolah motif untuk perancangan batik tulis adalah jenis wildstyle, bubble, dan tagging. Jenis graffiti yang dipakai masing-masig pada desain berupa kombinasi dari jenis graffiti tersebut. Pemilihan warna dibuat lebih beragam dan tidak terpaku pada warna-warna batik tulis.

Pengolahan visual batik dibuat menjadi beberapa kategori streetfood agar memudahkan dalam membuat desain. Pembagian kategori streetfood berdasar karakter khas makanan. Kategori desain yang dibuat diantaranya adalah: gorengan, makanan manis, makanan berat, minuman, makanan dengan tusuk, dan kombinasi beberapa jenis streetfo$o d$. Kategori makanan manis berupa graffiti dan visual dari martabak, roti bakar, kue pukis, kue putu, dan klepon. Kategori makanan dengan tusuk berupa graffiti dan visual dari cilok, siomay, telur gulung, dan bakso bakar. Kategori gorengan desain yang dibuat berupa graffiti dan visual gorengan seperti cireng, bakwan, tahu bakso, pastel, dan pisang goreng. Kategori makanan berat berupa graffiti dan visual dari bakso, pempek, bubur ayam, dan nasi goreng. Kategori minuman berupa graffiti dan visual dari es dawet, wedang ronde, es pisang ijo, dan es doger. Perancangan batik menghasilkan enam desain, yang dua diantaranya direalisasikan menjadi produk busana berupa baju atasan dan satu berupa kain batik.

Desain dibuat dengan menggunakan master berukuran $29,7 \mathrm{~cm} \times 42 \mathrm{~cm}$ dengan pengulangan satu langkah. Produk batik menggunakan kain primissima dengan pewarna jenis remasol. 

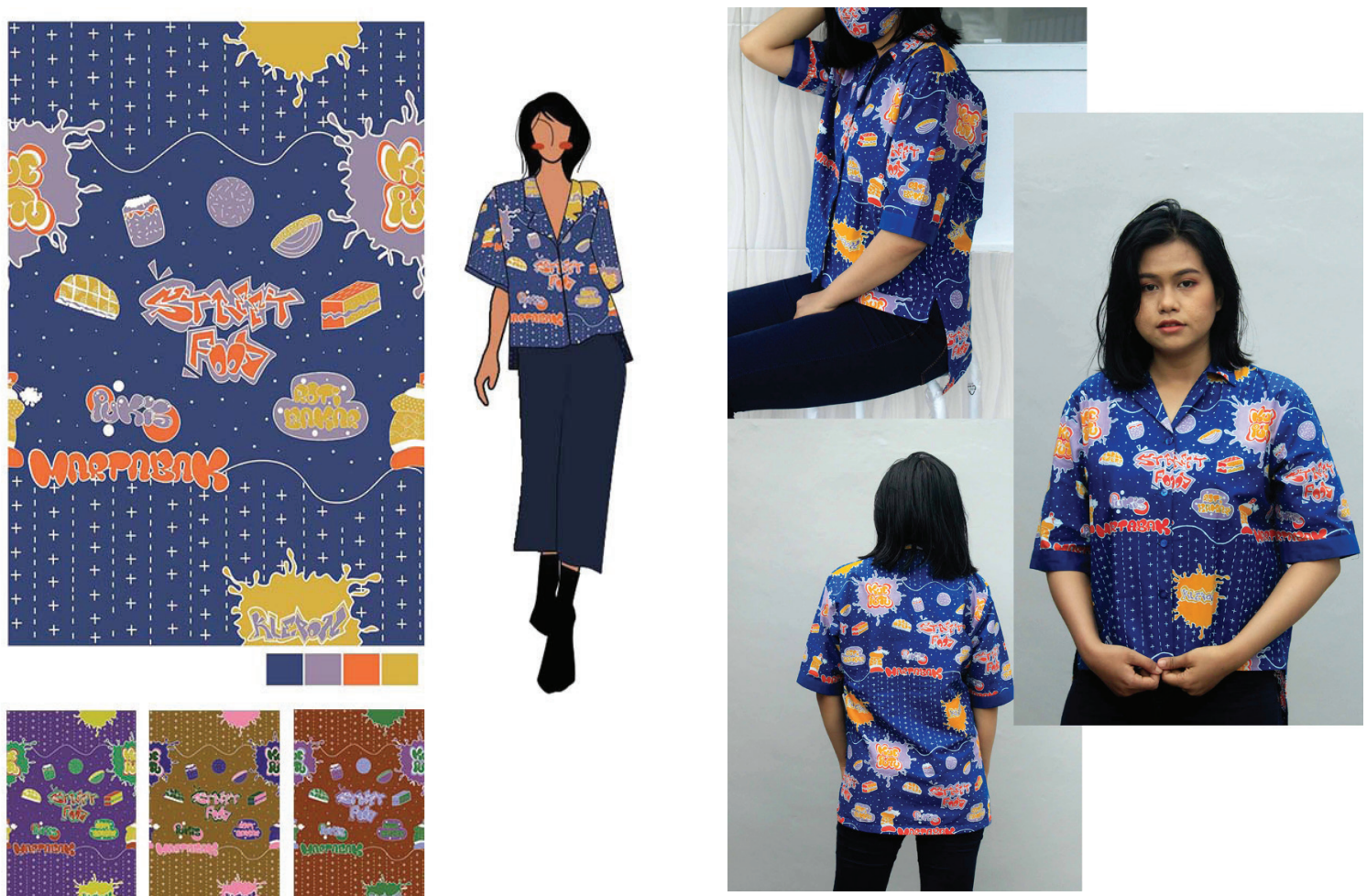

Gambar 3. Layout desain 1 dan foto produk

Motif batik pada desain tersebut berupa graffiti dengan mengambil tema streetfood dengan kategori makanan manis. Makanan manis merupakan jajanan yang mudah dijumpai di pedagang kaki lima maupun di pasar tradisional. Motif dibuat dengan menggunakan graffiti jenis wildstyle dan bubble. Motif pendukung berupa visual dari makanan manis, yaitu martabak, klepon, roti bakar, pukis, dan kue putu. Motif pendukung lain berupa visual dari kaleng cat kaleng semprot (pilox). Pada latar diberi isen-isen agar ciri khas visual batik tetap muncul. Ukuran master desain untuk desain 1 adalah A3 $(29,7 \mathrm{x}$ $42 \mathrm{~cm}$ ) dengan pengulangan satu langkah. Desain 1 direalisasikan menjadi produk busana wanita dengan teknik batik tulis.
Desain menggunakan motif berupa graffiti dari jenis wildstyle dan tagging dengan kata atau kalimat berupa makanan dengan tusuk. Makanan dengan tusuk ini banyak dijumpai di sekitar lingkungan sekolah. Jenis graffiti wildstyle terdapat pada motif dengan tulisan street food, sate, dan cilok. Sedangkan jenis tagging pada tulisan telur gulung dan bakso bakar. Motif berupa graffiti menjadi motif utama dalam perancangan batik tulis ini. Selain graffiti, motif pendukung lain adalah visual dari jajanan tusukan, cat kaleng semprot, gambar retakan untuk mendukung visual graffiti. Terdapat isen- isen cecek telu dan sisik pada latarnya sebagai ciri khas dari batik. Ukuran master pada dessain 2 adalah $29,7 \mathrm{~cm}$ x $42 \mathrm{~cm}$ degan pengulangan satu langkah. Realisasi desain 2 berupa produk kain batik tulis dengan ukuran kain $200 \mathrm{~cm}$ x $115 \mathrm{~cm}$. 

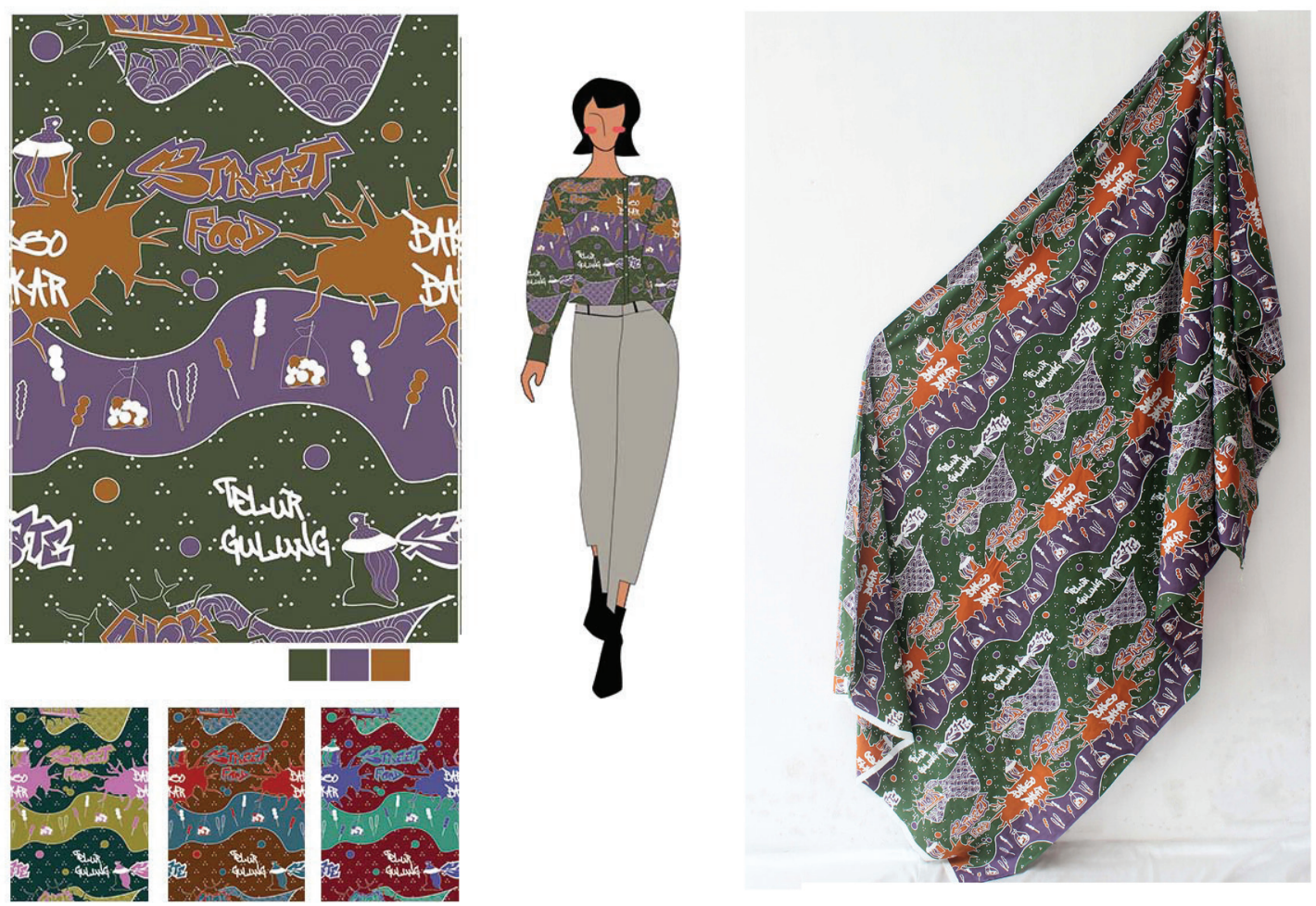

Gambar 4. Layout desain 2 dan foto produk

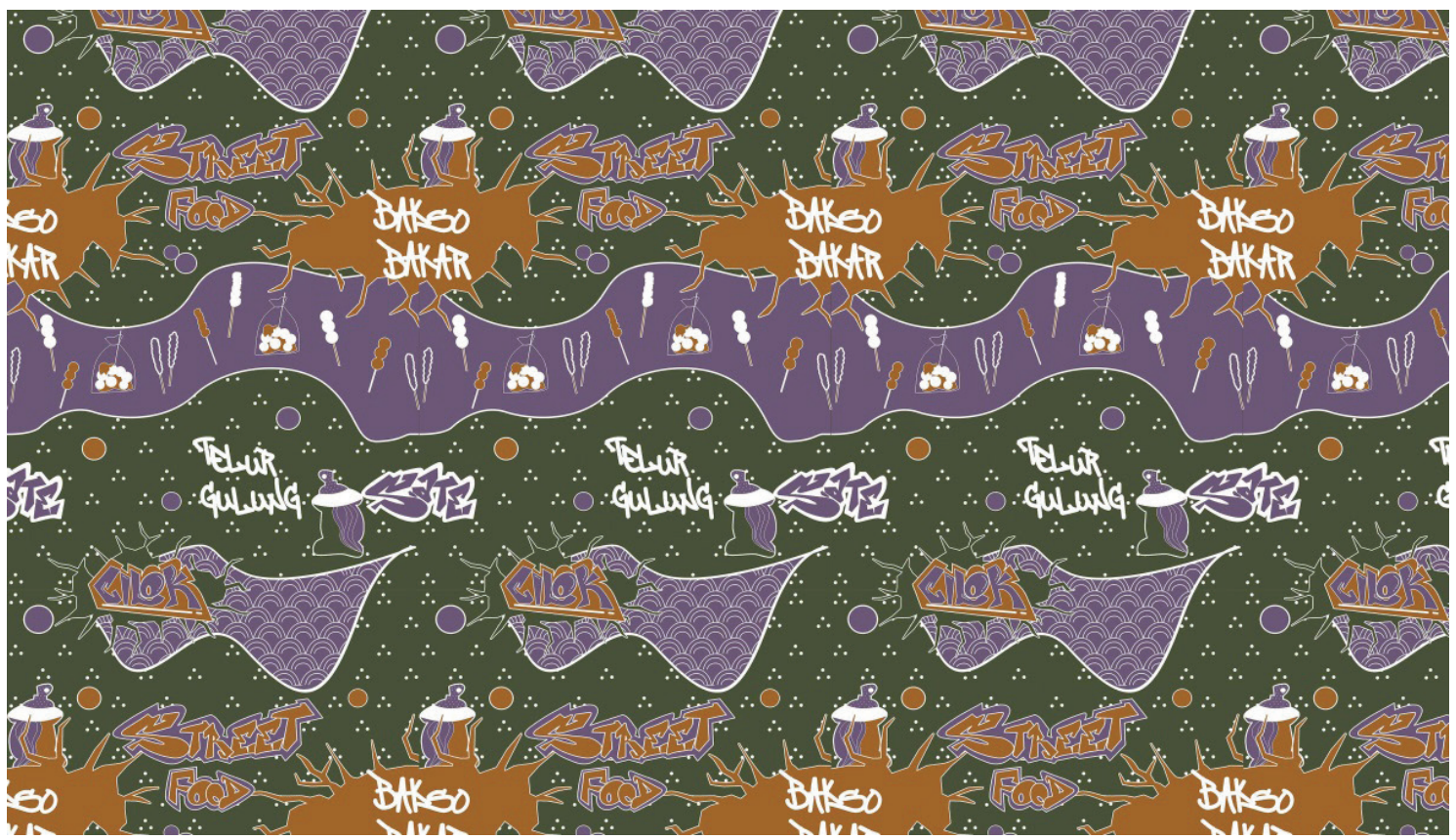

Gambar 5. Komposisi dan repetisi satu langkah 


\section{KESIMPULAN}

Hasil perancangan batik dengan memanfaatkan visual graffiti direalisasikan menjadi dua produk dan empat desain lainnya berupa visualisasi desain. Produk pertama, perancangan batik diaplikasikan menjadi busana ready to wear wanita dengan rentang usia 1925 tahun dengan desain yang kasual. Desain fesyen yang kasual mampu menonjolkan visual dari motif batik yang telah diolah. Produk kedua direalisasikan menjadi kain batik dengan ukuran $250 \mathrm{~cm}$ x $115 \mathrm{~cm}$.

\section{DAFTAR PUSTAKA}

Kaneva, N. 2011. Nation Branding: Toward an Agenda for Critical Research. International Journal of Communication 5 (2011), 117-141

Naguib, S. 2016. Engaged Ephemeral Art: Street Art and the Egyptian Arab Spring. Transcultural Studies 2016/2

Natanhia, C. A. 2016. Kekayaan Bahari Indonesia Sebagai Sumber Ide Perancangan Batik Gaya Doodle. Surakarta: Universitas Sebelas Maret

Poespo, G. 2009. A to Z Istilah Fashion. Jakarta: PT Gramedia Pustaka Utama
Prasetyo. 2016. Karakteristik Motif Batik Kendal Interpretasi dari Wilayah dan Letak Geografis, Jurnal Imajinasi.

Riyanto, A. A. 2003. Teori Busana. Bandung : Yapemdo

Rizali, N. 2018. Metode Perancangan Tekstil. Surakarta: UNS Press

Rockower, P. 2014. The State of Gastrodiplomacy. Public Diplomacy Magazine, 11(Winter), 13-16

Santosa, D. H. 2002. Batik: Pengaruh Zaman dan Lingkungan. Solo: Danar Hadi

Susanto, M. 2012. DIKSI RUPA: Kumpulan Istilah dan Gerakan Seni Rupa. Yogyakarta : DictiArt Lab \& Djagad Art House

Tsoumas, J. 2011. The aesthetic impact of graffiti art on modern Greek urban landscape. Ángulo Recto. Vol. 3, No. 2

Wibowo, A. S. 2014. Desain Motif Batik Kontemporer dengan Sumber Ide Robot. Surakarta: Universitas Sebelas Maret

Wicandra, O. B. \& Angkadjaja, S. N. 2005. Efek Ekologi Visual dan Sosio Kultural Melalui Graffiti Artistik di Surabaya, Jurnal Nirmana.

Winarno, F. G. 1993. Makanan Jajanan. Laporan Akhir Proyek Makanan Jajanan. Bogor: Institut Pertanian Bogor. 